\title{
Serum uric acid on admission cannot predict long-term outcome of critically ill patients: a retrospective cohort study
}

This article was published in the following Dove Press journal:

Therapeutics and Clinical Risk Management

\author{
Qinchang Chen ${ }^{1, *}$ \\ Kai Huang ${ }^{2, *}$ \\ Lingling $\mathrm{Li}^{2}$ \\ Xixia $\operatorname{Lin}^{2}$ \\ Cong Ding ${ }^{2}$ \\ Junrui Zhang ${ }^{3}$ \\ Qingui Chen'
}

'Department of Medical Intensive Care Unit, The First Affiliated Hospital, Sun Yat-sen University, Guangzhou, China; ${ }^{2}$ Division of Vascular and Thyroid Surgery, Sun Yat-Sen Memorial Hospital, Sun Yat-Sen University, Guangzhou, China; ${ }^{3}$ Guangzhou Institute of Standardization, Guangzhou, China

*These authors contributed equally to this work
Correspondence: Qingui Chen Department of Medical Intensive Care Unit, The First Affiliated Hospital, Sun Yat-sen University, No 58 Zhongshan Rd 2, 510080 Guangzhou, China

$\mathrm{Tel}+86 \quad$ I35 80442523

Email920835644@qq.com

\begin{abstract}
Purpose: We aimed to evaluate the association of serum uric acid on admission with long-term outcome of critically ill patients.

Materials and methods: We conducted a retrospective cohort study using data extracted from the Medical Information Mart for Intensive Care III database. The primary endpoint was 90-day mortality. Propensity score matching (PSM) was performed, and multivariate Cox regression analysis was used to adjust for potential confounders. Receiver operating characteristic (ROC) curves were also used to assess the mortality predictions.

Results: A total of 2,123 patients were included finally with a PSM cohort consisting of 556 90-day non-survivors matched 1:1 with 556 90-day survivors. No statistically significant difference of median admission uric acid was observed between the two groups (survivors $5.50 \mathrm{mg} / \mathrm{dL}$ vs non-survivors $5.60 \mathrm{mg} / \mathrm{dL}, p=0.536$ ). ROC area under the curve was 0.511 (95\% confidence interval [CI] 0.477-0.545), suggesting that uric acid had poor discriminative powers for predicting 90-day mortality. No significant association between uric acid and 90-day mortality was found (hazard ratio $1.00,95 \%$ CI $0.98-1.03, p=0.6835$ ).
\end{abstract}

Conclusion: Serum uric acid on intensive care unit admission failed to predict 90 -day mortality of critically ill patients.

Keywords: uric acid, critical care, mortality, risk factors

\section{Introduction}

Uric acid, the end product of an exogenous pool of purines, which functions as either an antioxidant or a pro-oxidant, has been reported as a predictor of outcomes in multiple diseases. ${ }^{1-4}$ Related research studies focused mainly on cardiovascular disease and found that uric acid might serve as a biomarker of severity of coronary artery disease in patients with acute coronary syndrome, cardiovascular mortality, 1 -year mortality of patients with acute coronary syndromes treated with percutaneous coronary intervention, and might improve the prognostic accuracy of some clinical models. ${ }^{5-8}$ The prognostic and predictive value of uric acid was also explored in type 2 diabetic patients and patients who had open heart surgery., ${ }^{9} 10$ However, the value of initial serum uric acid on admission in critically ill patients seems limited. Akbar et al reported that elevated uric acid levels in patients with sepsis are associated with an increased risk of acute kidney injury and acute respiratory distress syndrome, but Zhu et al found that there was no correlation between the initial levels of serum uric acid and prognosis of infection in critically ill patients. ${ }^{11,12}$ Meanwhile, it has been reported that no relationship was found between serum uric acid and 
short-term mortality of critically ill patients. ${ }^{13,14}$ To the best of our knowledge, there is no research to evaluate the association of serum uric acid on intensive care unit (ICU) admission with long-term outcome of critically ill patients. Thus, we performed a retrospective cohort study using a modifiable data mining technique applied to the publicly available Medical Information Mart for Intensive Care III (MIMIC-III) database, aiming to clarify whether there is an association between admission serum uric acid levels and long-term outcome. ${ }^{15}$

\section{Materials and methods Study design and data sources}

We conducted a retrospective cohort study using data extracted from the MIMIC-III database, which is a large publicly available database consisting of de-identified health-related data of patients who had stayed in the ICU of Beth Israel Deaconess Medical Center between 2001 and 2012. Access to database has been approved by the institutional review boards of both Beth Israel Deaconess Medical Center and Massachusetts Institute of Technology Affiliates. No informed consent was required on the deidentified patients.

\section{Participants}

Adult patients (aged $\geq 18$ years) of first hospital admission and first ICU admission were considered and included, but patients staying at ICU for $<1$ day and patients without admission serum uric acid records were excluded. In addition, patients whose death was earlier than ICU admission time and patients whose length of hospital stay was less than length of ICU stays were excluded in order to exclude potential typographical errors and records of organ donor account (Figure 1).

\section{Variables}

We applied Structured Query Language to extract data from the database mainly by using codes from the MIMIC Code Repository. ${ }^{16,24}$ Age, sex, ICU mortality and hospital mortality, length of ICU stay and length of hospital stay, 28-day mortality and 90-day mortality, admission serum uric acid (admission was defined as within 24 hours after ICU admission), Simplified Acute Physiology Score II (SAPS II), the Elixhauser comorbidities, and the Elixhauser Comorbidity Index (State Inpatient Database [SID]30) were extracted or calculated. ${ }^{17-19}$ Missing components for the calculation of SAPS II were treated as normal (usually 0). Because the database has had date of birth of patients who are older than

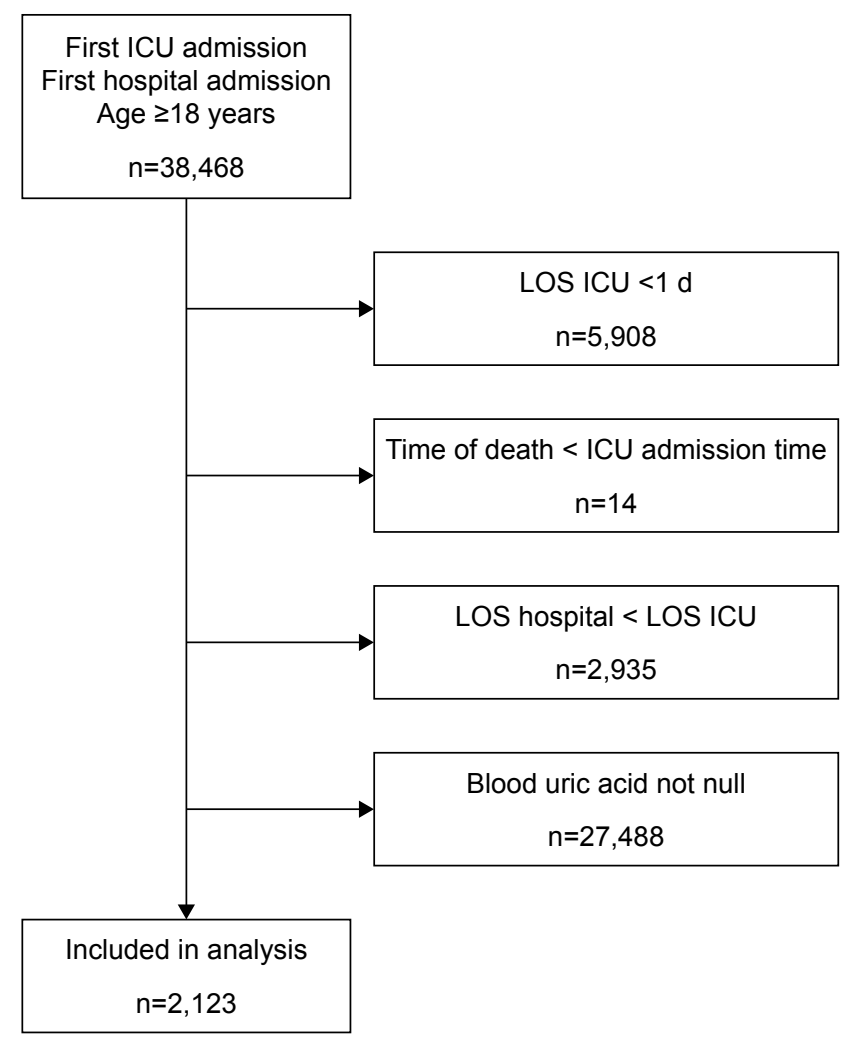

Figure I Flow chart of the study.

Abbreviations: ICU, intensive care unit; LOS, length of stay.

89 years shifted to exactly 300 years before to obscure their age, we corrected them (age $-300+89)$ before analysis.

\section{Outcome measures}

Ninety-day mortality after ICU admission was chosen as the primary end point, and 28-day mortality, hospital mortality, and ICU mortality were secondary outcomes. ICU mortality was determined only by the first ICU stay.

\section{Propensity score matching (PSM)}

We grouped the study subjects as survivors and non-survivors according to their 90-day survival status after ICU admission. The propensity score for each patient was calculated to estimate their probability of death during the first 90 days after ICU admission by using multivariable logistic regression models given the following covariates: gender, age, SAPS II, Elixhauser Comorbidity Index (SID30), sepsis (based on International Classification of Diseases, Ninth Revision [ICD-9] codes), mechanical ventilation on the first day, renal replacement therapy on the first day, congestive heart failure, cardiac arrhythmias, valvular disease, pulmonary circulation disorder, peripheral vascular disorder, hypertension, paralysis, other neurological disease, chronic pulmonary disease, uncomplicated diabetes, complicated 
diabetes, hypothyroidism, renal failure, liver disease, peptic ulcer, acquired immune deficiency syndrome, lymphoma, metastatic cancer, solid tumor, rheumatoid arthritis, coagulopathy, obesity, weight loss, fluid and electrolyte disorders, blood loss anemia, deficiency anemia, alcohol abuse, drug abuse, psychoses, and depression. Matching was performed with the use of a 1:1 matching protocol without replacement (greedy-matching algorithm), with a caliper width equal to 0.05 of the standard deviation of the logit of the propensity score. The overlap of the distribution of the propensity scores across survivors and non-survivors groups is shown in Figure S1.

\section{Statistical analysis}

For continuous variables, data were expressed as median and interquartile range (IQR) unless otherwise stated. For categorical variables, data were shown as numbers and percentages. Comparison of continuous and categorical variables was performed using Kruskal-Wallis and chi-square (or Fisher's exact) tests, respectively. We used receiver operating characteristic (ROC) curves to evaluate the prognostic predictive value of serum uric acid for 90-day mortality and other outcomes and used the Kaplan-Meier (K-M) method and log-rank tests to compare survival differences among patients of different admission serum uric acid levels. Variables associated with 90 -day mortality were evaluated by univariate Cox regression analysis, and those with a $p$-value $<0.1$ were considered in multivariable Cox regression model. Considering the expected collinearity between comorbidities and the Elixhauser Comorbidity Index (SID30), we would choose only either one of them to be enrolled into one adjusted model when variables are potentially significant $(p<0.1)$ in univariate analysis. Age was not included in the multivariable regression analysis since it was factored into SAPS II. Multivariable Cox regression model was performed to evaluate the association of serum uric acid on 90-day mortality and 28-day mortality, and multivariable logistic regression model was used to examine the association between hospital mortality and ICU mortality. $p$-values of $<0.05$ were considered to indicate statistical significance. Empower(R) (www. empowerstats.com; X\&Y solutions, Inc., Boston, MA, USA) and R software, version 3.4 .3 (http://www.r-project.org; R Foundation for Statistical Computing, Vienna, Austria) were used for statistical analyses.

\section{Results}

\section{Patient characteristics}

A total of 2,123 patients were included (Figure 1). As shown in Table 1, the median age of the study patients was
64.09 years (IQR 51.39-75.74 years) and 1,219 of the 2,123 cases $(57.42 \%)$ were male. The median admission serum uric acid was $5.40 \mathrm{mg} / \mathrm{dL}$ (IQR 3.80-7.90 mg/dL) with a median SAPS II score of 39 (IQR 30-49). Among them, 239 (11.26\%) patients were diagnosed with sepsis based on ICD-9 codes and 1,032 (48.61\%) patients required mechanical ventilation on admission. The five most common comorbidities were fluid and electrolyte disorders (38.48\%), congestive heart failure (20.35\%), deficiency anemia $(20.16 \%)$, cardiac arrhythmias (20.07\%), and coagulopathy (19.31\%). The 90-day mortality was $27.23 \%$ with 578 non-survivors and 1,545 survivors. The length of ICU stay and hospital stay was 3.79 (IQR 2.01-9.19) and 14.69 (IQR 8.05-26.37) days, respectively. Non-survivors had significantly higher SAPS II $(p<0.001)$. No statistically significant difference was observed in serum uric acid between survivors and non-survivors.

\section{Characteristics of the PSM cohort}

A total of 556 non-survivors were successfully matched with one control. Characteristics of PSM cohort are shown in Table 2. There was no statistically significant difference between survivors and non-survivors in age, gender, SAPS II on admission, Elixhauser Comorbidity Index (SID30), and comorbidities $(p>0.05)$, and no statistically significant difference was found on serum uric acid between survivors and non-survivors.

\section{Survival status of patients with different serum uric acid levels on admission}

Patients were grouped according to their serum uric acid levels on admission. The K-M survival curves presented in Figure 2 showed that there was no difference in the survival rate among different serum uric acid levels on admission (log-rank test: $p=0.88$ ) after PSM. The K-M survival curves of 28-day mortality are shown in Figure S2.

\section{ROC curve analysis}

As shown in Figure 3, the area under the ROC curve (AUC) of admission serum uric acid for discrimination of 90-day survivors and non-survivors was 0.522 (95\% confidence interval [CI] 0.494-0.550) and 0.511 (95\% CI 0.477-0.545) for all patients and PSM cohort, respectively. ROC curve analysis of other outcomes also indicated a poor predictive value of serum uric acid.

\section{Association between serum uric acid levels on admission and ICU outcomes}

Results of univariate Cox regression analysis of all patients and PSM cohort are presented in Tables S1 and S2, 
Table I Characteristics and comparison between survivors and non-survivors of all patients

\begin{tabular}{|c|c|c|c|c|}
\hline Variable & $\begin{array}{l}\text { All patients } \\
(n=2,123)\end{array}$ & $\begin{array}{l}\text { Survivors } \\
(n=1,545)\end{array}$ & $\begin{array}{l}\text { Non-survivors } \\
(n=578)\end{array}$ & $p$-value \\
\hline Age (years) & $64.09(51.39-75.74)$ & $62.11(48.68-73.83)$ & $68.97(57.79-79.52)$ & $<0.001$ \\
\hline Male & $1,219(57.42 \%)$ & 895 (57.93\%) & $324(56.06 \%)$ & 0.437 \\
\hline ICU mortality & I $87(8.8 \mid \%)$ & $0(0.00 \%)$ & 187 (32.35\%) & $<0.001$ \\
\hline Hospital mortality & $379(17.85 \%)$ & $4(0.26 \%)$ & $375(64.88 \%)$ & $<0.001$ \\
\hline Length of ICU stay (days) & $3.79(2.01-9.19)$ & $3.47(1.94-9.14)$ & $4.2 I(2.3 \mid-9.3 I)$ & 0.001 \\
\hline Length of hospital stay (days) & 14.69 (8.05-26.37) & $14.32(7.90-26.00)$ & I5.84 (9.03-27.50) & 0.051 \\
\hline Uric acid on admission (mg/dL) & $5.40(3.80-7.90)$ & $5.30(3.80-7.80)$ & $5.70(3.90-8.00)$ & 0.119 \\
\hline SAPS II on admission & 39 (30-49) & $36.00(28.00-45.00)$ & $47.00(39.00-56.00)$ & $<0.001$ \\
\hline Elixhauser Comorbidity Index (SID30) & $11.00(4.00-23.00)$ & II.00 (0.00-20.00) & $17.00(\mid 1.00-28.00)$ & $<0.001$ \\
\hline Sepsis (based on ICD-9 codes) & $239(11.26 \%)$ & $132(8.54 \%)$ & $107(\mid 8.51 \%)$ & $<0.001$ \\
\hline Mechanical ventilation on first day & $\mathrm{I}, 032(48.61 \%)$ & $754(48.80 \%)$ & $278(48.10 \%)$ & 0.772 \\
\hline Renal replacement therapy on first day & 135 (6.36\%) & $93(6.02 \%)$ & $42(7.27 \%)$ & 0.295 \\
\hline \multicolumn{5}{|l|}{ Comorbidities } \\
\hline Congestive heart failure & $432(20.35 \%)$ & $268(17.35 \%)$ & 164 (28.37\%) & $<0.001$ \\
\hline Cardiac arrhythmias & $426(20.07 \%)$ & $268(I 7.35 \%)$ & I 58 (27.34\%) & $<0.001$ \\
\hline Valvular disease & $109(5.13 \%)$ & $67(4.34 \%)$ & $42(7.27 \%)$ & 0.006 \\
\hline Pulmonary circulation disorder & $110(5.18 \%)$ & $70(4.53 \%)$ & $40(6.92 \%)$ & 0.027 \\
\hline Peripheral vascular disorder & I85 (8.7।\%) & $130(8.41 \%)$ & $55(9.52 \%)$ & 0.423 \\
\hline Hypertension & 239 (11.26\%) & 169 (10.94\%) & $70(12.11 \%)$ & 0.447 \\
\hline Paralysis & $5 \mathrm{I}(2.40 \%)$ & $36(2.33 \%)$ & $15(2.60 \%)$ & 0.723 \\
\hline Other neurological disease & I $82(8.57 \%)$ & $127(8.22 \%)$ & $55(9.52 \%)$ & 0.343 \\
\hline Chronic pulmonary disease & $327(15.40 \%)$ & $238(15.40 \%)$ & 89 (I5.40\%) & 0.997 \\
\hline Uncomplicated diabetes & $365(17.19 \%)$ & $267(17.28 \%)$ & $98(16.96 \%)$ & 0.859 \\
\hline Complicated diabetes & I33 (6.26\%) & $96(6.21 \%)$ & $37(6.40 \%)$ & 0.874 \\
\hline Hypothyroidism & 170 (8.0I\%) & $126(8.16 \%)$ & $44(7.61 \%)$ & 0.682 \\
\hline Renal failure & 302 (I4.23\%) & $212(13.72 \%)$ & $90(15.57 \%)$ & 0.278 \\
\hline Liver disease & $152(7.16 \%)$ & $98(6.34 \%)$ & $54(9.34 \%)$ & 0.017 \\
\hline Peptic ulcer & I $(0.05 \%)$ & I (0.06\%) & $0(0.00 \%)$ & 1.000 \\
\hline AIDS & I5 (0.7I\%) & $10(0.65 \%)$ & $5(0.87 \%)$ & 0.569 \\
\hline Lymphoma & 89 (4.19\%) & $55(3.56 \%)$ & $34(5.88 \%)$ & 0.017 \\
\hline Metastatic cancer & $|2|(5.70 \%)$ & $54(3.50 \%)$ & 67 (II.59\%) & $<0.001$ \\
\hline Solid tumor & $59(2.78 \%)$ & $43(2.78 \%)$ & $16(2.77 \%)$ & 0.985 \\
\hline Rheumatoid arthritis & 49 (2.31\%) & 31 (2.01\%) & $18(3.11 \%)$ & 0.130 \\
\hline Coagulopathy & $410(19.31 \%)$ & $252(16.31 \%)$ & $158(27.34 \%)$ & $<0.001$ \\
\hline Obesity & $84(3.96 \%)$ & 61 (3.95\%) & $23(3.98 \%)$ & 0.974 \\
\hline Weight loss & I 27 (5.98\%) & $80(5.18 \%)$ & $47(8.13 \%)$ & $0.01 \mathrm{I}$ \\
\hline Fluid and electrolyte disorders & 817 (38.48\%) & $548(35.47 \%)$ & $269(46.54 \%)$ & $<0.001$ \\
\hline Blood loss anemia & 72 (3.39\%) & $65(4.21 \%)$ & 7 (1.21\%) & $<0.001$ \\
\hline Deficiency anemia & $428(20.16 \%)$ & 322 (20.84\%) & 106 (18.34\%) & 0.201 \\
\hline Alcohol abuse & $116(5.46 \%)$ & 91 (5.89\%) & 25 (4.33\%) & 0.158 \\
\hline Drug abuse & $56(2.64 \%)$ & 49 (3.17\%) & 7 (1.21\%) & 0.012 \\
\hline Psychoses & $68(3.20 \%)$ & $59(3.82 \%)$ & $9(1.56 \%)$ & 0.008 \\
\hline Depression & II2 (5.28\%) & 86 (5.57\%) & 26 (4.50\%) & 0.327 \\
\hline
\end{tabular}

Notes: Patients were grouped as survivors and non-survivors determined by 90 -day mortality status. Data are expressed as median (interquartile range) or $\mathrm{n}$ (\%) unless otherwise stated. Kruskal-Wallis and chi-square (or Fisher's exact) tests were used to analyse continuous and categorical variables, respectively. Statistical significance $(p<0.05)$ is shown in bold.

Abbreviations: ICU, intensive care unit; SAPS II, Simplified Acute Physiology Score II; ICD-9, International Classification of Diseases, Ninth Revision; AIDS, acquired immune deficiency syndrome.

respectively. As shown in Table 3, multivariable regression analysis of PSM cohort indicated that serum uric acid was not an independent risk factor of 90-day mortality (hazard ratio [HR] 1.00, 95\% CI 0.98-1.03, $p=0.6835$ ), 28-day mortality (HR 1.01, 95\% CI 0.98-1.04, $p=0.4894$ ), hospital mortality (odds ratio [OR] 1.01, 95\% CI 0.97-1.04, $p=0.6099$ ), and ICU mortality (OR 1.01, 95\% CI $0.97-1.05, p=0.6934$ ).
Results of regression analysis of all patients are also shown in Table 3.

\section{Discussion}

For the first time, the present study evaluated the association between serum uric acid on ICU admission and longterm outcome of critically ill patients. Results of the study 
Table 2 Characteristics and comparison between survivors and non-survivors of PSM cohort

\begin{tabular}{|c|c|c|c|c|}
\hline Variable & $\begin{array}{l}\text { All patients } \\
(n=I, I \mid 2)\end{array}$ & $\begin{array}{l}\text { Survivors } \\
(n=556)\end{array}$ & $\begin{array}{l}\text { Non-survivors } \\
(n=556)\end{array}$ & $p$-value \\
\hline Age (years) & $69.00(57.80-79.00)$ & $69.13(58.27-78.71)$ & $68.97(57.44-79.54)$ & 0.920 \\
\hline Male & $621(55.85 \%)$ & $306(55.04 \%)$ & $315(56.65 \%)$ & 0.587 \\
\hline ICU mortality & $176(15.83 \%)$ & $0(0.00 \%)$ & $176(31.65 \%)$ & $<0.001$ \\
\hline Hospital mortality & $358(32.19 \%)$ & $3(0.54 \%)$ & $355(63.85 \%)$ & $<0.001$ \\
\hline Length of ICU stay (days) & $4.08(2.16-9.48)$ & $3.81(2.08-9.42)$ & $4.29(2.39-9.49)$ & 0.164 \\
\hline Length of hospital stay (days) & $15.98(8.82-28.13)$ & 16.18 (8.64-29.04) & I 5.87 (9.09-27.52) & 0.687 \\
\hline Uric acid on admission (mg/dL) & $5.50(3.80-8.20)$ & $5.50(3.70-8.30)$ & $5.60(3.90-7.90)$ & 0.536 \\
\hline SAPS II on admission & $46.00(37.00-55.00)$ & $45.00(37.00-55.00)$ & $46.00(38.00-55.00)$ & 0.202 \\
\hline Elixhauser Comorbidity Index (SID30) & $18.00(10.00-28.00)$ & $19.00(9.75-28.00)$ & $17.00(10.75-27.25)$ & 0.428 \\
\hline Sepsis (based on ICD-9 codes) & $184(16.55 \%)$ & $83(14.93 \%)$ & I0I (I8.17\%) & 0.146 \\
\hline Mechanical ventilation on first day & $531(47.75 \%)$ & $263(47.30 \%)$ & $268(48.20 \%)$ & 0.764 \\
\hline Renal replacement therapy on first day & $86(7.73 \%)$ & $45(8.09 \%)$ & $4 \mathrm{l}(7.37 \%)$ & 0.653 \\
\hline \multicolumn{5}{|l|}{ Comorbidities } \\
\hline Congestive heart failure & $321(28.87 \%)$ & 167 (30.04\%) & 154 (27.70\%) & 0.390 \\
\hline Cardiac arrhythmias & $297(26.71 \%)$ & 148 (26.62\%) & 149 (26.80\%) & 0.946 \\
\hline Valvular disease & $80(7.19 \%)$ & $38(6.83 \%)$ & $42(7.55 \%)$ & 0.642 \\
\hline Pulmonary circulation disorder & $80(7.19 \%)$ & $41(7.37 \%)$ & $39(7.01 \%)$ & 0.816 \\
\hline Peripheral vascular disorder & $105(9.44 \%)$ & $52(9.35 \%)$ & $53(9.53 \%)$ & 0.918 \\
\hline Hypertension & $139(12.50 \%)$ & $71(12.77 \%)$ & $68(12.23 \%)$ & 0.786 \\
\hline Paralysis & $30(2.70 \%)$ & I 6 (2.88\%) & $14(2.52 \%)$ & $0.7 I I$ \\
\hline Other neurological disease & $106(9.53 \%)$ & $53(9.53 \%)$ & $53(9.53 \%)$ & 1.000 \\
\hline Chronic pulmonary disease & $183(16.46 \%)$ & 95 (I7.09\%) & $88(15.83 \%)$ & 0.571 \\
\hline Uncomplicated diabetes & $194(17.45 \%)$ & 97 (I7.45\%) & $97(17.45 \%)$ & 1.000 \\
\hline Complicated diabetes & $72(6.47 \%)$ & $39(7.01 \%)$ & $33(5.94 \%)$ & 0.465 \\
\hline Hypothyroidism & $92(8.27 \%)$ & $51(9.17 \%)$ & $4 \mathrm{l}(7.37 \%)$ & 0.276 \\
\hline Renal failure & $182(16.37 \%)$ & $95(17.09 \%)$ & $87(15.65 \%)$ & 0.517 \\
\hline Liver disease & 97 (8.72\%) & $48(8.63 \%)$ & $49(8.81 \%)$ & 0.915 \\
\hline AIDS & $12(1.08 \%)$ & 7 (I.26\%) & $5(0.90 \%)$ & 0.773 \\
\hline Lymphoma & $68(6.12 \%)$ & $34(6.12 \%)$ & $34(6.12 \%)$ & 1.000 \\
\hline Metastatic cancer & $99(8.90 \%)$ & 44 (7.91\%) & $55(9.89 \%)$ & 0.247 \\
\hline Solid tumor & $35(3.15 \%)$ & $19(3.42 \%)$ & $16(2.88 \%)$ & 0.606 \\
\hline Rheumatoid arthritis & 35 (3.15\%) & 18 (3.24\%) & $17(3.06 \%)$ & 0.864 \\
\hline Coagulopathy & $292(26.26 \%)$ & 146 (26.26\%) & I 46 (26.26\%) & 1.000 \\
\hline Obesity & 42 (3.78\%) & $20(3.60 \%)$ & 22 (3.96\%) & 0.753 \\
\hline Weight loss & $93(8.36 \%)$ & 47 (8.45\%) & $46(8.27 \%)$ & 0.914 \\
\hline Fluid and electrolyte disorders & $509(45.77 \%)$ & $258(46.40 \%)$ & 251 (45.I4\%) & 0.674 \\
\hline Blood loss anemia & II (0.99\%) & $4(0.72 \%)$ & 7 (I.26\%) & 0.547 \\
\hline Deficiency anemia & $218(19.60 \%)$ & I I 4 (20.50\%) & 104 (I8.7I\%) & 0.450 \\
\hline Alcohol abuse & 48 (4.32\%) & 25 (4.50\%) & 23 (4.14\%) & 0.768 \\
\hline Drug abuse & $12(1.08 \%)$ & $5(0.90 \%)$ & $7(1.26 \%)$ & 0.773 \\
\hline Psychoses & $2 \mathrm{l}(1.89 \%)$ & $12(2.16 \%)$ & $9(1.62 \%)$ & 0.509 \\
\hline Depression & $5 \mathrm{I}(4.59 \%)$ & 26 (4.68\%) & $25(4.50 \%)$ & 0.886 \\
\hline
\end{tabular}

Notes: Patients were grouped as survivors and non-survivors determined by 90 -day mortality status. Data are expressed as median (interquartile range) or $\mathrm{n}$ (\%) unless otherwise stated. Kruskal-Wallis and chi-square (or Fisher's exact) tests were used to analyze continuous and categorical variables, respectively. Statistical significance $(p<0.05)$ is shown in bold.

Abbreviations: PSM, propensity score matching; ICU, intensive care unit; SAPS II, Simplified Acute Physiology Score II; ICD-9, International Classification of Diseases, Ninth Revision; AIDS, acquired immune deficiency syndrome.

indicated that serum uric acid on admission cannot predict long-term outcome of critically ill patients.

It is interesting to find no correlation between serum uric acid with clinical outcomes of critically ill patients, since many studies had reported the prognostic predictive value of serum uric acid in many clinical conditions. For example, uric acid was found to be an independent predictor of cardiovascular outcomes and increase prognostic accuracy of Cox models in hypertensives with normal renal function which allowed a risk reclassification according to a recent report of Perticone et al. ${ }^{8}$ Given serum uric acid is increased in respiratory disease, especially in the presence of hypoxia and systemic inflammation, many researchers wondered whether it could serve as a biomarker of prognostic predictive value. ${ }^{20}$ Nagaya et al reported that serum uric acid levels correlate with the severity and the mortality of primary pulmonary 

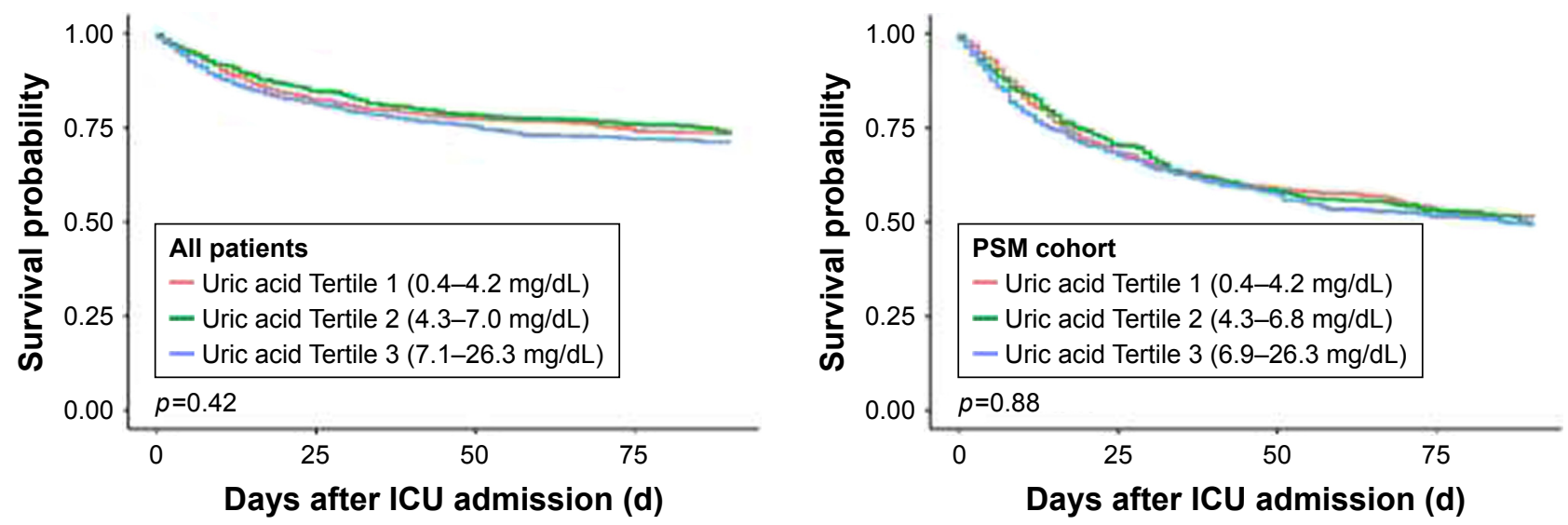

\begin{tabular}{|c|c|c|c|}
\hline \multicolumn{4}{|c|}{ Number at risk } \\
\hline 685 & 566 & 531 & 512 \\
\hline 725 & 615 & 570 & 551 \\
\hline 713 & 583 & 539 & 514 \\
\hline 0 & 25 & 50 & 75 \\
\hline
\end{tabular}

\begin{tabular}{|c|c|c|c|}
\hline \multicolumn{2}{|c|}{ Number at risk } & \multirow[b]{2}{*}{213} & \multirow[b]{2}{*}{194} \\
\hline 361 & 248 & & \\
\hline 380 & 268 & 222 & 202 \\
\hline 371 & 255 & 214 & 191 \\
\hline 0 & 25 & 50 & 75 \\
\hline
\end{tabular}

Figure 2 Kaplan-Meier survival curve by different levels of uric acid of all patients and PSM cohort. Abbreviations: ICU, intensive care unit; PSM, propensity score matching.

hypertension. ${ }^{21}$ Bartziokas et al found that serum uric acid was associated with increased 30-day mortality and risk for future acute exacerbation of chronic obstructive pulmonary disease. ${ }^{22}$ Ergun et al reported that high serum uric acid levels are predictive for not only long-term mortality but also for short-term mortality. ${ }^{23}$ However, in terms of critically ill patients, only a few studies were conducted to explore the value of uric acid and most of the conclusions were negative. ${ }^{12-14}$ Considering that most of the previous studies

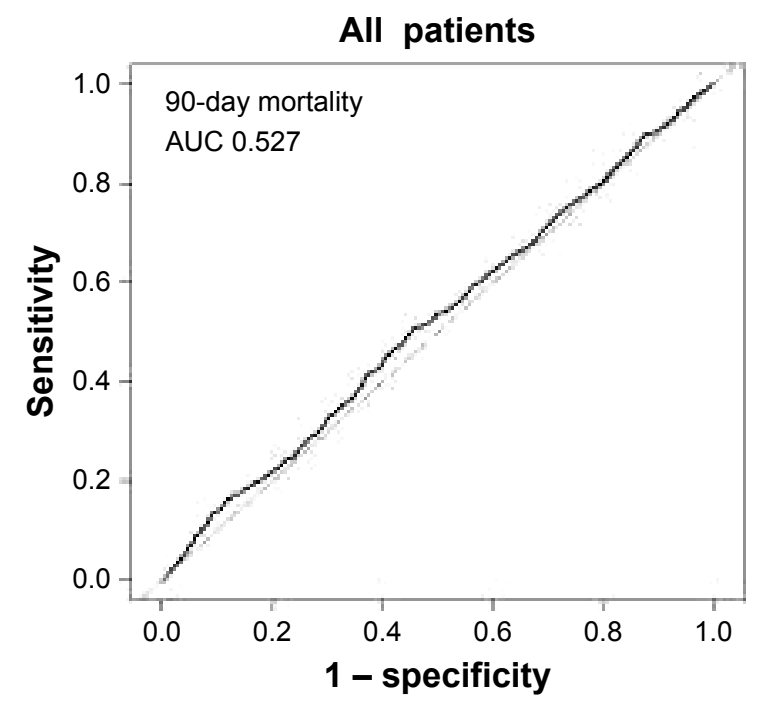

evaluated only the short-term outcomes with limited sample sizes, we conducted this present study aiming to evaluate the predictive value of serum uric acid for long-term outcome of critically ill patients. In our study, we included over 2,000 patients which made enough adjustment for confounders available and improved statistical power. Meanwhile, we performed PSM to further minimize the potential selection bias. Results of all patients and PSM cohort were consistent and provided a solid conclusion of the association between

Figure 3 (Continued)

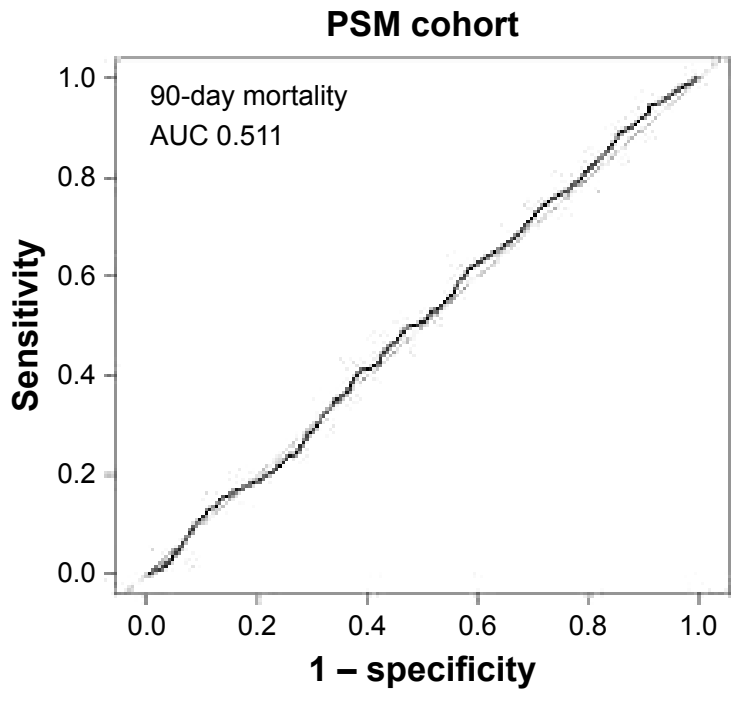



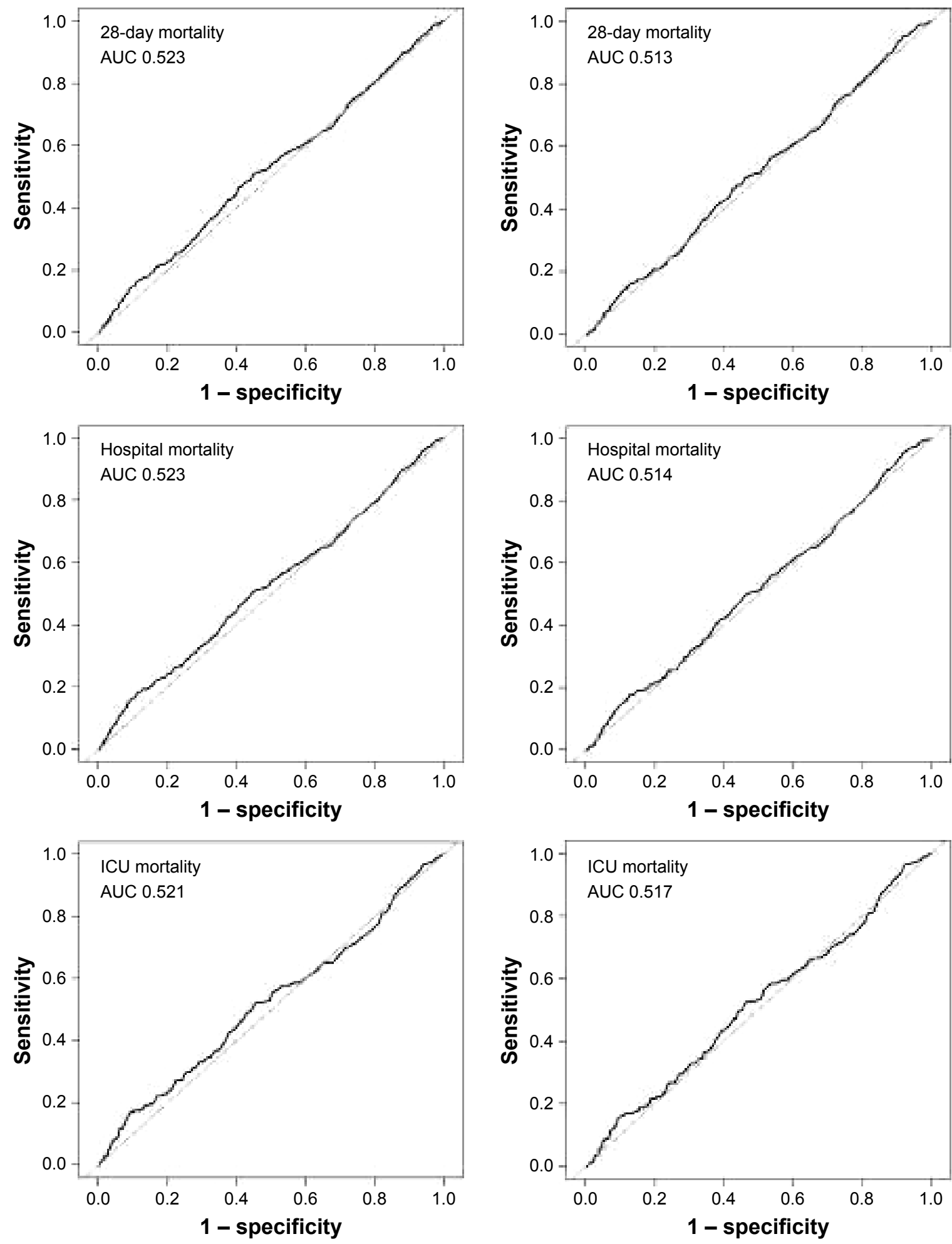

Figure 3 ROC curves of admission serum uric acid for prediction of clinical outcomes in all patients and the PSM cohort.

Abbreviations: ROC curves, receiver operating characteristic curves; ICU, intensive care unit; AUC, area under the ROC curves; PSM, propensity score matching.

serum uric acid and 90-day mortality for critically ill patients, although negative. We also examined some short-term outcomes in the study, and the results were consistent with previous studies.
Although the findings in our study were informative, there were several limitations in the present study. First, given the observational nature of our study, it is not possible to adjust all potential confounders. Although we considered 
Table 3 Association of uric acid with 90-day mortality, 28-day mortality, ICU mortality, and hospital mortality

\begin{tabular}{|c|c|c|c|}
\hline Subjects & HR/OR & $95 \% \mathrm{Cl}$ & $p$-value \\
\hline \multicolumn{4}{|l|}{ All patients } \\
\hline \multicolumn{4}{|l|}{ 90-day mortality } \\
\hline Non-adjusted & 1.02 & $1.00-1.05$ & 0.0552 \\
\hline Model I & 1.00 & $0.98-1.03$ & 0.7743 \\
\hline Model II & 1.01 & $0.98-1.03$ & 0.5735 \\
\hline \multicolumn{4}{|l|}{ 28-day mortality } \\
\hline Non-adjusted & 1.03 & $1.00-1.06$ & $0.057 \mid$ \\
\hline Model I & 1.01 & $0.98-1.04$ & $0.628 I$ \\
\hline Model II & 1.01 & $0.98-1.04$ & 0.5785 \\
\hline \multicolumn{4}{|l|}{ ICU mortality } \\
\hline Non-adjusted & 1.03 & $0.99-1.08$ & 0.1198 \\
\hline Model I & 1.01 & $0.96-1.05$ & 0.8157 \\
\hline Model II & 1.00 & $0.96-1.05$ & 0.9105 \\
\hline \multicolumn{4}{|l|}{ Hospital mortality } \\
\hline Non-adjusted & 1.04 & $1.00-1.07$ & 0.0301 \\
\hline Model I & 1.01 & $0.97-1.04$ & 0.6263 \\
\hline Model II & 1.01 & $0.97-1.04$ & 0.6924 \\
\hline \multicolumn{4}{|l|}{ PSM cohort } \\
\hline \multicolumn{4}{|l|}{ 90-day mortality } \\
\hline Non-adjusted & 1.01 & $0.98-1.03$ & 0.6160 \\
\hline Model I & 1.00 & $0.98-1.03$ & 0.6835 \\
\hline \multicolumn{4}{|l|}{ 28-day mortality } \\
\hline Non-adjusted & 1.01 & $0.98-1.04$ & 0.3784 \\
\hline Model I & 1.01 & $0.98-1.04$ & 0.4894 \\
\hline \multicolumn{4}{|l|}{ ICU mortality } \\
\hline Non-adjusted & 1.02 & $0.98-1.07$ & 0.3709 \\
\hline Model I & 1.01 & $0.97-1.05$ & 0.6934 \\
\hline \multicolumn{4}{|l|}{ Hospital mortality } \\
\hline Non-adjusted & 1.02 & $0.98-1.05$ & $0.375 I$ \\
\hline Model I & 1.01 & $0.97-1.04$ & 0.6099 \\
\hline
\end{tabular}

Notes: Association of uric acid with 90-day mortality and 28-day mortality was analyzed using Cox regression models, and associations of uric acid with ICU mortality and hospital mortality were analyzed using logistic regression models. For all patients, model I was adjusted for SAPS II, Elixhauser Comorbidity Index (SID30), and sepsis based on ICD-9 codes; model II was adjusted for SAPS II, sepsis based on ICD-9 codes, congestive heart failure, cardiac arrhythmias, valvular disease, pulmonary circulation disorder, liver disease, lymphoma, metastatic cancer, coagulopathy, weight loss, fluid and electrolyte disorders, blood loss anemia, drug abuse, and psychoses. For PSM cohort, model was adjusted for SAPS II. Statistical significance $(p<0.05)$ is shown in bold.

Abbreviations: ICU, intensive care unit; HR, hazard ratio; OR, odds ratio; $\mathrm{Cl}$, confidence interval; PSM, propensity score matching; SAPS II, Simplified Acute Physiology Score II; ICD-9, International Classification of Diseases, Ninth Revision.

many variables known to affect the outcomes, unmeasured confounders may have affected our results. As we know, the reference value of serum uric acid is different between male and female; hence, gender must be considered in the $\mathrm{K}-\mathrm{M}$ survival curves. In fact, the results were consistent even after grouped by sex (data not shown), but there were still other potential confounders such as renal replacement therapy on the first day, fluid and electrolyte disorders, which made it difficult to take all these confounders into consideration in the K-M curves. And since there were too many specific primary diagnoses for all the patients, we categorized the primary diseases as several comorbidities
(Tables 1 and 2) to make it easier to adjust and analyze. However, it was indisputable that some unmeasured confounders such as gout, uremia, and other uric acid metabolic disorder might still have affected the results. In addition, as a retrospective database study, it was difficult to account for the potential effect of therapy before ICU admission on serum uric acid levels, because such information was usually not documented. Thus, further well-designed prospective study is needed to confirm our results. Second, the present study included data from only one ICU center, which might limit the external applicability of the study results. Third, we found no association between serum uric acid on admission and long-term outcomes of critically ill patients, but whether the changes of serum uric acid would be associated with the clinical outcomes of the patients remained unknown.

\section{Conclusion}

This large retrospective cohort study found that there was no statistically significant association of admission serum uric acid with 90-day mortality of ICU patients, providing a stronger confirmation of the controversial issue. However, further prospective basic and clinical research studies are still needed especially to reveal the underlined mechanisms and to evaluate the potential predictive value of changes of uric acid.

\section{Acknowledgments}

The study was supported by National Natural Science Foundation of China (No 81670066), Major Science and Technology Planning Project of Guangdong Province (No 2016A020216009), Natural Science Foundation of Guangdong Province China (No 2015A030310346), and Special Funds for the Cultivation of Guangdong College Students' Scientific and Technological Innovation ("Climbing Program" Special Funds).

\section{Author contributions}

Qingui Chen designed the study and was the primary author of the manuscript. Qinchang Chen and Kai Huang mainly performed data extraction and statistical analysis. All authors contributed toward data analysis, drafting, and critically revising the paper, gave final approval of the version to be published, and agreed to be accountable for all aspects of the work.

\section{Disclosure}

The authors report no conflicts of interest in this work. 


\section{References}

1. El Ridi R, Tallima H. Physiological functions and pathogenic potential of uric acid: a review. J Adv Res. 2017;8(5):487-493.

2. Martinon F. Update on biology: uric acid and the activation of immune and inflammatory cells. Curr Rheumatol Rep. 2010;12(2):135-141.

3. Ames BN, Cathcart R, Schwiers E, Hochstein P. Uric acid provides an antioxidant defense in humans against oxidant- and radical-caused aging and cancer: a hypothesis. Proc Natl Acad Sci US A. 1981;78(11): 6858-6862.

4. Sautin YY, Johnson RJ. Uric acid: the oxidant-antioxidant paradox. Nucleosides Nucleotides Nucleic Acids. 2008;27(6):608-619.

5. Duran M, Kalay N, Akpek M, et al. High levels of serum uric acid predict severity of coronary artery disease in patients with acute coronary syndrome. Angiology. 2012;63(6):448-452.

6. Dutta A, Henley W, Pilling LC, Wallace RB, Melzer D. Uric acid measurement improves prediction of cardiovascular mortality in later life. $J$ Am Geriatr Soc. 2013;61(3):319-326.

7. Ndrepepa G, Braun S, Haase HU, et al. Prognostic value of uric acid in patients with acute coronary syndromes. Am J Cardiol. 2012;109(9): 1260-1265.

8. Perticone M, Tripepi G, Maio R, et al. Risk reclassification ability of uric acid for cardiovascular outcomes in essential hypertension. Int $J$ Cardiol. 2017;243:473-478.

9. Zoppini G, Targher G, Negri C, et al. Elevated serum uric acid concentrations independently predict cardiovascular mortality in type 2 diabetic patients. Diabetes Care. 2009;32(9):1716-1720.

10. Gaipov A, Solak Y, Turkmen K, et al. Serum uric acid may predict development of progressive acute kidney injury after open heart surgery. Ren Fail. 2015;37(1):96-102.

11. Akbar SR, Long DM, Hussain K, et al. Hyperuricemia: an early marker for severity of illness in sepsis. Int J Nephrol. 2015;2015:301021.

12. Zhu HC, Cao RL. The relationship between serum levels of uric acid and prognosis of infection in critically ill patients. World J Emerg Med. 2012;3(3):186-190.
13. Hooman N, Mehrazma M, Nakhaii S, et al. The value of serum uric acid as a mortality prediction in critically ill children. Iran J Pediatr. 2010;20(3):323-329.

14. Aminiahidashti H, Bozorgi F, Mousavi SJ, Sedighi O, Gorji AM, Rashidian H. Serum uric acid level in relation to severity of the disease and mortality of critically ill patients. $J$ Lab Physicians. 2017;9(1):42-46.

15. Johnson AE, Pollard TJ, Shen L, et al. MIMIC-III, a freely accessible critical care database. Sci Data. 2016;3:160035.

16. Johnson A, Stone DJ, Celi LA, Pollard TJ. The MIMIC code repository: enabling reproducibility in critical care research. J Am Med Inform Assoc. 2017;25(1):32-39.

17. Le Gall JR, Lemeshow S, Saulnier F. A new Simplified Acute Physiology Score (SAPS II) based on a European/North American multicenter study. JAMA. 1993;270(24):2957-2963.

18. Steiner C, Elixhauser A, Schnaier J. The healthcare cost and utilization project: an overview. Eff Clin Pract. 2002;5(3):143-151.

19. Thompson NR, Fan Y, Dalton JE, et al. A new Elixhauser-based comorbidity summary measure to predict in-hospital mortality. Med Care. 2015;53(4):374-379.

20. Ruggiero C, Cherubini A, Ble A, et al. Uric acid and inflammatory markers. Eur Heart J. 2006;27(10):1174-1181.

21. Nagaya N, Uematsu M, Satoh T, et al. Serum uric acid levels correlate with the severity and the mortality of primary pulmonary hypertension. Am J Respir Crit Care Med. 1999;160(2):487-492.

22. Bartziokas K, Papaioannou AI, Loukides S, et al. Serum uric acid as a predictor of mortality and future exacerbations of COPD. Eur Respir J. 2014;43(1):43-53.

23. Ergun R, Ergan B. Does serum uric acid levels predict in-hospital mortality in severe COPD exacerbations? Eur Respir J. 2015;46 (Suppl 59):PA395.

24. MIMIC Code Repository [homepage on the Internet]. Cambridge: Laboratory for Computational Physiology, Massachusetts Institute of Technology; 2018 [updated March 15, 2018]. Available from: http:// github.com/MIT-LCP/mimic-code. Accessed April 10, 2018. 


\section{Supplementary materials}

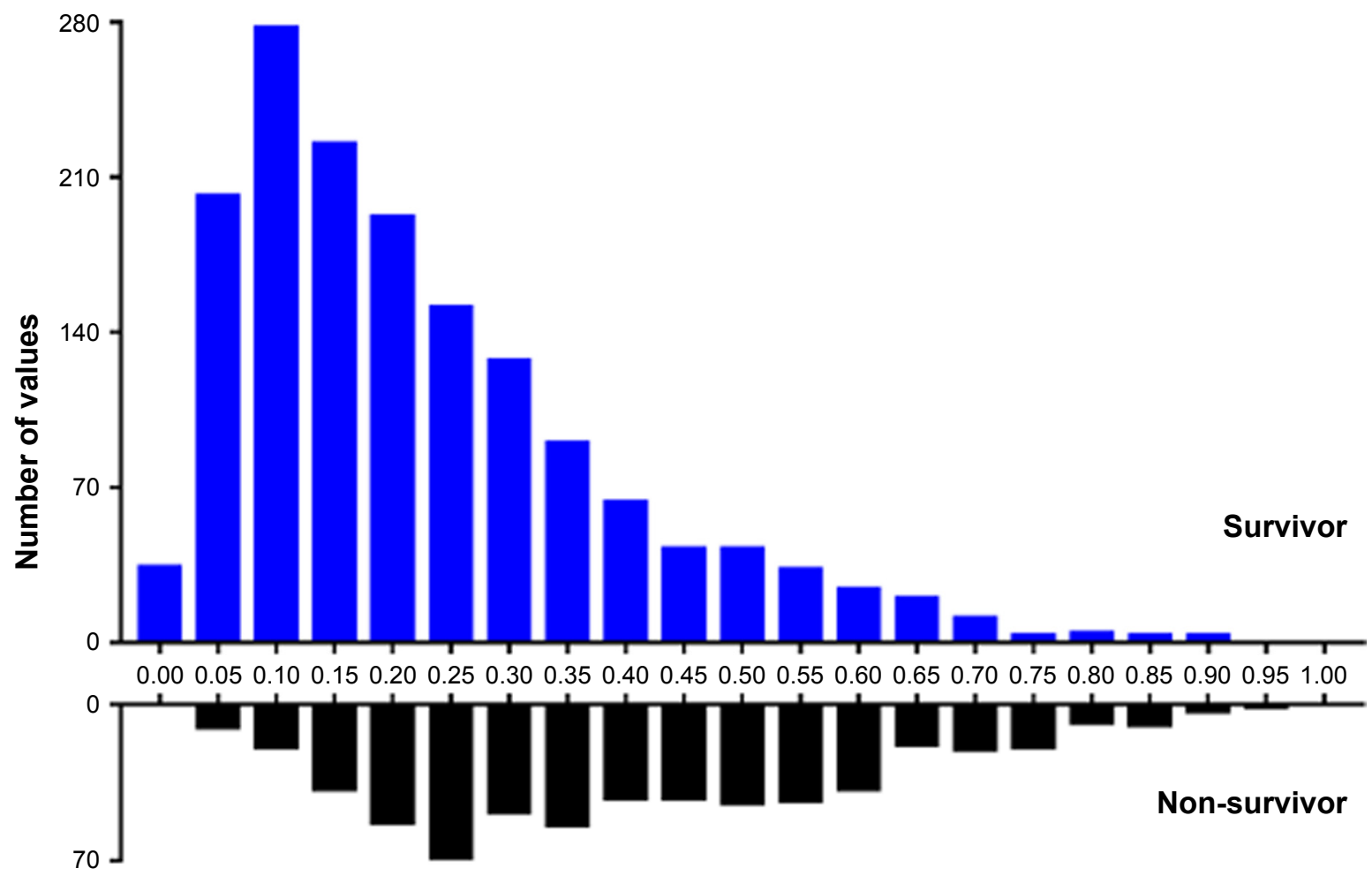

Figure SI Distribution of propensity scores.
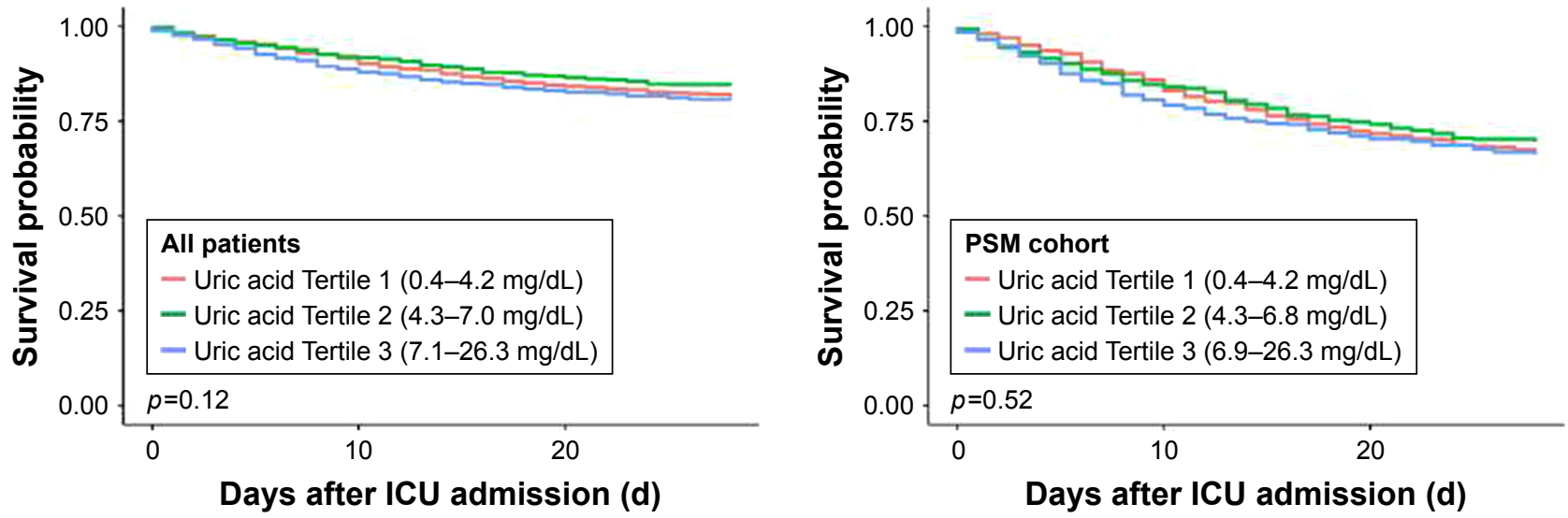

$=\underbrace{\text { Number at risk }}_{0}$\begin{tabular}{ccc}
685 & 628 & 579 \\
725 & 667 & 630 \\
713 & 633 & 593 \\
\hline 0 & 10 & 20 \\
& Days after ICU admission (d)
\end{tabular}

\begin{tabular}{|c|c|c|}
\hline \multicolumn{3}{|c|}{ Number at risk } \\
\hline 361 & 310 & 261 \\
\hline 380 & 322 & 284 \\
\hline 371 & 299 & 264 \\
\hline 0 & 10 & 20 \\
\hline
\end{tabular}

Figure S2 Kaplan-Meier survival curve of 28-day mortality.

Abbreviations: ICU, intensive care unit; PSM, propensity score matching. 
Table SI Univariate Cox regression analysis of all patients on 90-day mortality

\begin{tabular}{|c|c|c|c|c|c|c|c|}
\hline \multirow{2}{*}{\multicolumn{4}{|c|}{ 90-day mortality }} & \multirow{3}{*}{$\begin{array}{l}\text { Variables } \\
\text { Liver disease }\end{array}$} & \multirow{3}{*}{ HR } & \multirow{3}{*}{$95 \% \mathrm{Cl}$} & \multirow{3}{*}{ p-value } \\
\hline & & & & & & & \\
\hline Variables & HR & $95 \% \mathrm{Cl}$ & $p$-value & & & & \\
\hline Age (years) & 1.02 & $1.02-1.03$ & $<0.0001$ & No & 1.0 & & \\
\hline Gender & & & & Yes & 1.38 & $1.04-1.82$ & 0.0246 \\
\hline Male & 1.0 & & & Peptic ulcer & & & \\
\hline Female & 1.07 & $0.91-1.26$ & 0.4272 & No & 1.0 & & \\
\hline SAPS II & 1.04 & $1.03-1.04$ & $<0.0001$ & Yes & 0.00 & $0.00-\operatorname{Inf}$ & 0.9866 \\
\hline Sepsis (based on ICD-9 codes) & & & & AIDS & & & \\
\hline No & 1.0 & & & No & 1.0 & & \\
\hline Yes & 2.02 & $1.63-2.49$ & $<0.0001$ & Yes & 1.19 & $0.49-2.88$ & 0.6938 \\
\hline Mechanical ventilation on first day & & & & Lymphoma & & & \\
\hline No & 1.0 & & & No & 1.0 & & \\
\hline Yes & 0.99 & $0.84-1.16$ & 0.8727 & Yes & $\mathrm{I} .47$ & $1.04-2.08$ & 0.0294 \\
\hline Renal replacement therapy on first day & & & & Metastatic can & & & \\
\hline No & 1.0 & & & No & 1.0 & & \\
\hline Yes & 1.22 & $0.89-1.67$ & 0.2207 & Yes & 2.63 & $2.04-3.39$ & $<0.0001$ \\
\hline Uric acid $(\mathrm{mg} / \mathrm{dL})$ & 1.02 & $1.00-1.05$ & 0.0552 & Solid tumor & & & \\
\hline Elixhauser Comorbidity Index (SID30) & 1.04 & $1.03-1.04$ & $<0.0001$ & No & 1.0 & & \\
\hline Comorbidities & & & & Yes & 0.99 & $0.6 \mathrm{I}-\mathrm{I} .64$ & 0.9836 \\
\hline Congestive heart failure & & & & Rheumatoid a & & & \\
\hline No & 1.0 & & & No & 1.0 & & \\
\hline Yes & 1.67 & $1.40-2.0 \mid$ & $<0.000 \mathrm{I}$ & Yes & 1.44 & $0.90-2.30$ & 0.1302 \\
\hline Cardiac arrhythmias & & & & Coagulopathy & & & \\
\hline No & 1.0 & & & No & 1.0 & & \\
\hline Yes & 1.60 & $1.33-1.92$ & $<0.000 \mathrm{I}$ & Yes & 1.71 & $1.43-2.06$ & $<\mathbf{0 . 0 0 0 1}$ \\
\hline Valvular disease & & & & Obesity & & & \\
\hline No & 1.0 & & & No & 1.0 & & \\
\hline Yes & 1.53 & $1.12-2.10$ & 0.0078 & Yes & 1.04 & $0.68-1.57$ & 0.8648 \\
\hline Pulmonary circulation disorder & & & & Weight loss & & & \\
\hline No & 1.0 & & & No & 1.0 & & \\
\hline Yes & 1.41 & $1.02-1.95$ & 0.0357 & Yes & 1.42 & $1.06-1.92$ & 0.0205 \\
\hline Peripheral vascular disorder & & & & Fluid and elect & & & \\
\hline No & 1.0 & & & No & 1.0 & & \\
\hline Yes & 1.10 & $0.83-1.45$ & 0.5042 & Yes & 1.47 & $1.25-1.73$ & $<0.0001$ \\
\hline Hypertension & & & & Blood loss ane & & & \\
\hline No & 1.0 & & & No & 1.0 & & \\
\hline Yes & 1.08 & $0.84-1.38$ & 0.5602 & Yes & 0.31 & $0.15-0.65$ & 0.0021 \\
\hline Paralysis & & & & Deficiency ane & & & \\
\hline No & 1.0 & & & No & 1.0 & & \\
\hline Yes & 1.08 & $0.65-1.8 \mid$ & $0.758 I$ & Yes & 0.87 & $0.70-1.07$ & 0.1879 \\
\hline Other neurological disease & & & & Alcohol abuse & & & \\
\hline No & 1.0 & & & No & 1.0 & & \\
\hline Yes & 1.12 & $0.85-1.48$ & 0.4238 & Yes & 0.76 & $0.5 \mathrm{I}-1.13$ & 0.1709 \\
\hline Chronic pulmonary disease & & & & Drug abuse & & & \\
\hline No & 1.0 & & & No & 1.0 & & \\
\hline Yes & 1.01 & $0.8 \mathrm{I}-\mathrm{I} .27$ & 0.9319 & Yes & 0.41 & $0.20-0.87$ & 0.0198 \\
\hline Uncomplicated diabetes & & & & Psychoses & & & \\
\hline No & 1.0 & & & No & 1.0 & & \\
\hline Yes & 0.97 & $0.78-1.20$ & 0.7806 & Yes & 0.45 & $0.24-0.88$ & 0.0188 \\
\hline Complicated diabetes & & & & Depression & & & \\
\hline No & 1.0 & & & No & 1.0 & & \\
\hline Yes & 1.01 & $0.73-|.4|$ & 0.9442 & Yes & 0.81 & $0.55-1.20$ & 0.2953 \\
\hline Hypothyroidism & & & & Note: Statistical & $n$ in bold & & \\
\hline No & 1.0 & & & Abbreviations: $\mathrm{H}$ & ce inter & val; SAPS II, Sim & plified Acute \\
\hline Yes & 0.93 & $0.68-1.27$ & 0.6455 & Physiology Score II & ification & of Diseases-Ni & nth Revision; \\
\hline Renal failure & & & & AIDS, acquired imr & & & \\
\hline No & 1.0 & & & & & & \\
\hline Yes & 1.11 & $0.89-1.39$ & 0.3518 & & & & \\
\hline
\end{tabular}

Table SI (Continued)

Abbreviations: HR, hazard ratio; $\mathrm{Cl}$, confidence interval; SAPS II, Simplified Acute Physiology Score II; ICD-9, International Classification of Diseases-Ninth Revision; (1) 
Table S2 Univariate Cox regression analysis of PSM cohort on 90-day mortality

\begin{tabular}{|c|c|c|c|}
\hline & HR & $95 \% \mathrm{Cl}$ & $p$-value \\
\hline Age (years) & 1.00 & $0.99-1.00$ & 0.5566 \\
\hline \multicolumn{4}{|l|}{ Gender } \\
\hline Male & 1.0 & & \\
\hline Female & 0.95 & $0.80-1.13$ & 0.5646 \\
\hline SAPS II & 1.01 & $1.00-1.01$ & 0.0606 \\
\hline \multicolumn{4}{|l|}{ Sepsis (based on ICD-9 codes) } \\
\hline No & 1.0 & & \\
\hline Yes & 1.16 & $0.93-1.43$ & 0.1866 \\
\hline \multicolumn{4}{|l|}{ Mechanical ventilation on first day } \\
\hline No & 1.0 & & \\
\hline Yes & 1.04 & $0.88-1.23$ & 0.6044 \\
\hline \multicolumn{4}{|l|}{ Renal replacement therapy on first day } \\
\hline No & 1.0 & & \\
\hline Yes & 0.98 & $0.7 \mid-1.34$ & 0.8889 \\
\hline Uric acid $(\mathrm{mg} / \mathrm{dL})$ & 1.01 & $0.98-1.03$ & 0.6160 \\
\hline Elixhauser Comorbidity Index (SID30) & 1.00 & $0.99-1.00$ & 0.3701 \\
\hline \multicolumn{4}{|l|}{ Comorbidities } \\
\hline \multicolumn{4}{|l|}{ Congestive heart failure } \\
\hline No & 1.0 & & \\
\hline Yes & 0.91 & $0.76-1.10$ & 0.3262 \\
\hline \multicolumn{4}{|l|}{ Cardiac arrhythmias } \\
\hline No & 1.0 & & \\
\hline Yes & 0.99 & $0.82-1.19$ & 0.9074 \\
\hline \multicolumn{4}{|l|}{ Valvular disease } \\
\hline No & 1.0 & & \\
\hline Yes & 1.05 & $0.77-1.44$ & $0.767 \mid$ \\
\hline \multicolumn{4}{|l|}{ Pulmonary circulation disorder } \\
\hline No & 1.0 & & \\
\hline Yes & 0.94 & $0.68-1.30$ & 0.7088 \\
\hline \multicolumn{4}{|l|}{ Peripheral vascular disorder } \\
\hline No & 1.0 & & \\
\hline Yes & 0.97 & $0.73-1.29$ & 0.8432 \\
\hline \multicolumn{4}{|l|}{ Hypertension } \\
\hline No & 1.0 & & \\
\hline Yes & 0.93 & $0.72-1.19$ & 0.5546 \\
\hline \multicolumn{4}{|l|}{ Paralysis } \\
\hline No & 1.0 & & \\
\hline Yes & 0.88 & $0.52-1.50$ & 0.6503 \\
\hline \multicolumn{4}{|l|}{ Other neurological disease } \\
\hline No & 1.0 & & \\
\hline Yes & 0.96 & $0.72-1.27$ & 0.7778 \\
\hline \multicolumn{4}{|l|}{ Chronic pulmonary disease } \\
\hline No & 1.0 & & \\
\hline Yes & 0.97 & $0.77-1.21$ & 0.7744 \\
\hline \multicolumn{4}{|l|}{ Uncomplicated diabetes } \\
\hline No & 1.0 & & \\
\hline Yes & 0.98 & $0.79-1.22$ & 0.8543 \\
\hline \multicolumn{4}{|l|}{ Complicated diabetes } \\
\hline No & 1.0 & & \\
\hline Yes & 0.85 & $0.60-1.21$ & 0.3748 \\
\hline \multicolumn{4}{|l|}{ Hypothyroidism } \\
\hline No & 1.0 & & \\
\hline Yes & 0.83 & $0.60-1.13$ & $0.236 \mathrm{I}$ \\
\hline \multicolumn{4}{|l|}{ Renal failure } \\
\hline No & 1.0 & & \\
\hline Yes & 0.90 & $0.71-1.13$ & 0.3562 \\
\hline
\end{tabular}

Table S2 (Continued)

\begin{tabular}{|c|c|c|c|}
\hline & HR & $95 \% \mathrm{Cl}$ & $p$-value \\
\hline \multicolumn{4}{|c|}{ Liver disease } \\
\hline No & 1.0 & & \\
\hline Yes & 0.98 & $0.73-1.32$ & 0.9022 \\
\hline \multicolumn{4}{|l|}{ AIDS } \\
\hline No & 1.0 & & \\
\hline Yes & 0.72 & $0.30-1.73$ & 0.4603 \\
\hline \multicolumn{4}{|c|}{ Lymphoma } \\
\hline No & 1.0 & & \\
\hline Yes & 0.94 & $0.67-1.33$ & 0.7409 \\
\hline \multicolumn{4}{|c|}{ Metastatic cancer } \\
\hline No & 1.0 & & \\
\hline Yes & 1.14 & $0.86-1.50$ & 0.3634 \\
\hline \multicolumn{4}{|c|}{ Solid tumor } \\
\hline No & 1.0 & & \\
\hline Yes & 0.89 & $0.54-1.46$ & 0.6411 \\
\hline \multicolumn{4}{|c|}{ Rheumatoid arthritis } \\
\hline No & 1.0 & & \\
\hline Yes & 0.94 & $0.58-1.53$ & 0.8061 \\
\hline \multicolumn{4}{|c|}{ Coagulopathy } \\
\hline No & 1.0 & & \\
\hline Yes & 0.99 & $0.82-1.20$ & 0.9481 \\
\hline \multicolumn{4}{|c|}{ Obesity } \\
\hline No & 1.0 & & \\
\hline Yes & 1.17 & $0.76-1.79$ & 0.4717 \\
\hline \multicolumn{4}{|c|}{ Weight loss } \\
\hline No & 1.0 & & \\
\hline Yes & 0.93 & $0.69-1.26$ & 0.6577 \\
\hline \multicolumn{4}{|c|}{ Fluid and electrolyte disorders } \\
\hline No & 1.0 & & \\
\hline Yes & 0.96 & $0.8 \mathrm{I}-1.13$ & 0.6048 \\
\hline \multicolumn{4}{|c|}{ Blood loss anemia } \\
\hline No & 1.0 & & \\
\hline Yes & 1.27 & $0.60-2.67$ & 0.5344 \\
\hline \multicolumn{4}{|c|}{ Deficiency anemia } \\
\hline No & 1.0 & & \\
\hline Yes & 0.92 & $0.74-1.14$ & 0.4309 \\
\hline \multicolumn{4}{|c|}{ Alcohol abuse } \\
\hline No & 1.0 & & \\
\hline Yes & 0.94 & $0.62-1.43$ & 0.7775 \\
\hline \multicolumn{4}{|c|}{ Drug abuse } \\
\hline No & 1.0 & & \\
\hline Yes & 1.21 & $0.57-2.55$ & 0.6186 \\
\hline \multicolumn{4}{|c|}{ Psychoses } \\
\hline No & 1.0 & & \\
\hline Yes & 0.93 & $0.48-1.79$ & 0.8215 \\
\hline \multicolumn{4}{|c|}{ Depression } \\
\hline No & 1.0 & & \\
\hline Yes & 0.94 & $0.63-|.4|$ & 0.7814 \\
\hline
\end{tabular}

Abbreviations: PSM, propensity score matching; $\mathrm{HR}$, hazard ratio; $\mathrm{Cl}$, confidence interval; SAPS II, Simplified Acute Physiology Score II; ICD-9, International Classification of Diseases-Ninth Revision; AIDS, acquired immune deficiency syndrome; SID, State Inpatient Database. 
Therapeutics and Clinical Risk Management

Dovepress

\section{Publish your work in this journal}

Therapeutics and Clinical Risk Management is an international, peerreviewed journal of clinical therapeutics and risk management, focusing on concise rapid reporting of clinical studies in all therapeutic areas, outcomes, safety, and programs for the effective, safe, and sustained use of medicines. This journal is indexed on PubMed Central, CAS,

Base, Scopus and the Elsevier Bibliographic databases. The manuscript management system is completely online and includes a very quick and fair peer-review system, which is all easy to use. Visit http://www.dovepress.com/testimonials.php to read real quotes from published authors.

Submit your manuscript here: http://www.dovepress.com/therapeutics-and-clinical-risk-management-journal 